\title{
On the Influence and Inspiration of Local Culture on Chinese Modern Landscape Design
}

\author{
Xiaoqian YANG \\ ZhiXing College of HuBei University \\ Wuhan, P.R.China, 430000
}

\begin{abstract}
Modern landscape design is a disciplines combination of nature, culture, society, science and the arts. It needs to build with suitable spiritual culture, should be based on the practice of contemporary landscape, and captures the essence of the law of the spirit of Chinese culture, so that it is possible to make modern landscape Design good use. Category spiritual culture is science, art and morality. The use of our current theories to explain the concept of the material is good and the beautiful unity. Development of landscape design should be more emphasized on people, culture and natural harmony, emphasized the spirit of the modern landscape design of Chinese culture. China only reflects the cultural connotation of landscape design that only has real vitality, only reflecting the cultural characteristics of Chinese design gives a truly spiritual comfort and belonging. Chinese spiritual and cultural factors and the importance of understanding the development trend of modern landscape design have important guiding significance for the landscape design education. Pay attention to the spirit of Chinese culture landscape, image creation and reflect; seeking plot reflects China's landscape design that is the way of innovation and development of Chinese landscape design.
\end{abstract}

Keywords- Landscape Design; Spiritual Culture; Cultural Characteristics; Thinking; Spiritual Style; Development Trend

\section{INTRODUCTION}

We can see modern art and modern design have the same root, but the level of representation is not the same. Between the two phenomena is interpenetration and mutual influence. Modern art is beauty, as reflected in the value of modern consciousness. Modern design is reflected in the value of state in the form of the modern sense (modern values also include the value of modern culture). Modern design is always subject to the social object, economic factors and technical factors such as the individual limit compared with modern art that has some degree of lateness. Therefore, some people think that modern art painter who wanted to build a new painting system is encompassing the results by their own hands, but with modern practical art opened the curtain.

\section{AN INFLUENCE OF NATIONAL CULTURE AND MODERN LANDSCAPE DESIGN}

China has a long tradition of landscape, especially the South Classical Gardens is an extremely valuable cultural heritage. South classical gardens as the traditional model of national culture have compacted layout, color and elegance, with particular emphasis on the pursuit of artistic conception. Modern landscape design in China is a very young industry, and it has developed rapidly but there have been many problems. Talk about the traditional culture and modern landscape design view.

\section{A. Inheritance of Traditional Culture}

Tradition and modernity are not contradictory; modernization should inject new content for our traditional culture, rather than separate traditional culture and us. In the process of cultural heritage, it should be adapted to the era of innovation, tradition itself is not static, traditional culture is rooted in the national soil, is a dynamic process. Tradition must be new or foreign things that collide in a collision reorganization, updating, variation, in order to progress. Modern landscape design is a service to society, the benefit of humankind discipline, and it is a blend of past and present, history and modernity through. Heritage of traditional culture, not retro, but cannot simply copy, traditional culture and modern culture is in fact one of the sides of culture, tradition and modern together constitute the human survival activities. It a part of the cultural activities of traditional culture; it is another part of the traditional culture to amend and to supplement.

\section{B. The Concise View of Ancient Structure Elements and Create a Mood Space}

Modern landscape design is actually the traditional national culture of exploration and amendment, supplement, updating, people and nature through design coordination and harmony. Grasp the South classical garden landscaping elements and concisely on this basis, in order to adapt to the social and cultural needs of the present stage. Landscape designers should cherish ancestral traditions and culture gardening ideas, should inherit and explore traditional culture living things, should create their own cultural landscape and landscape features. Chinese classical gardens are "Music of Landscape,mountain and clean water " that is the basic idea of the design, the charm of nature and space to 
penetrate into the home environment. South classical gardens have always had a tradition of local conditions, extreme attention to the use of the original development of the natural beauty of scenery, every stone and the tree can be seen when leaving scene shade, slope built by mountain on the potential court. Amidst the beautiful southern, people aspire to live, but the climate is very different from the North and the South, living habits and preferences also have all kinds of differences, the case handle every detail of all focus on the same and different grasp of the structure with the appropriate scene of equal importance placed in position.

\section{LOCAL LANDSCAPE AND THE INFLUENCE OFMODERN LANDSCAPE DESIGN}

Local landscape including rural, home and traditional things refers to villages, houses and those who live a normal life of people in general. Before the main study is their living landscape, that is, farmers, artisans and workers constructed homes. Local landscape corresponds with the urban landscape; the main is a traditional distinction between new things. There are three elements of rural landscape in order to constitute. First, it refers to the presence in rural areas, within a relatively stable agricultural and pastoral area. Second, it is with a certain feudal elements, and feudal culture is closely linked. Third, the existence is only manual farming era. Local landscape is natural process of spatial patterns and lands as well as people who on the land formed adapt the way people take for life, which is a more comprehensive geographical complex. It is more a reflection of the relationship between man and nature areas and people.

Local landscape mirrors the history of local experience, through the landscape may reflect local historical and cultural background, but also includes a comprehensive reflection of the nation's style of an area, which reflects the local people in the geographic environment adapted to the integration. With the development of time, there are a lot of old things disappearing and changing, these things are usually not aware of the locals, and it just evolved slowly, and gradually formed a certain local landscape. In fact, the majority of China's culture from the local landscape, but we did not go to research and discovery, however, the study of the culture of our modern landscape design has a particularly important significance. It is a historical heritage, the historical experience of our ancestors survived, we need to analyzeand study finishing, from some of the more subtle areas and special perspective, we can really explore.

For a new perspective of landscape design, life is the landscape and whitened landscape.

The local landscape value said is vague and not specific enough, we have only one region to transform the local landscape or through our design to stand out, so our research is very valuable, and it has meaning and reality. You can help us understand the local landscape in modern planning and design process to fully take into account respect for people, how to meet more people for modern life and modern living environments. The starting point of modern landscape design is to take into account the habits of different groups of people in various regions to design.Usually some unusual or strange landscape design landscape design have the ultimate goal, and that will make people feel a novel, you can also have a blockbuster effect and give the left a deep impression, and sometimes this unique design will become the landmark buildings or monuments of a region. Those unusual landscapes sometimes contain some poetic things, and the text is somewhat similar for people to read. There is a beautiful and touching feeling, a lot of modern landscape design from technical and aesthetic considerations, and sometimes with the local culture Contact little background, this design will not get a good evaluation.we want to experience and need more thinking people in the design process, one can meet people's needs, We must also be combined with the reality of fully respecting human background. Planning and design should be based on human factors, a good grasp of the elements of human nature in order to design the perfect modern landscape; otherwise it will be eliminated by the people.

\section{INFLUENCE OFABSTRACT ART MODERN LANDSCAPE DESIGN}

The emergence of abstract art had a social consciousness abstract ideological activity, and geometry modeling pure form factors and composition, with a strong sense of the era of the Industrial Revolution in the revelation of a large machine production and formation. Affecting all areas of modern design, landscape design as an important branch of modern contemporary design has also experienced the direct impact of changes that brought about by the times. Each era design style formation, both with the social, cultural and economic development are closely linked, the whole atmosphere of an era is the era of soil design development, design also reflects the outlook of an era and the era features.

China's environmental landscape culture has a long history; no one nation has the aesthetic nature of the request. To a certain degree of cultural development of the nation, it will have their ownlandscape. The traditional landscape is based on people's material and spiritual needs arising. Chinese traditional garden design idea is to nature as an aesthetic object, which is mainly designed to mimic nature, to absorb the beauty of nature, to combine with artistic practices. For example, moderation thinks anything of nature and human and social development to the extreme but it will go. "Heaven" is the ideological basis for the ecological concept of ancient Chinese natural aesthetic ancient scientists analyzes that man and nature can live in peace get beauty. "Far as the stone path to the Han Mountain, where there still people live" the perfect ecological environment reflects the harmony between man and nature. Originated in ancient Chinese landscape on the natural environment of aesthetic choice, it attaches great importance to the relationship between man and nature. Chinese houses in the "Heaven" reasoning influence, from site selection, the overall layout of the indoor and outdoor environment design, furnishings, and even drawn and creates technology, reflects a simple ecological spirit, namely respect for nature, the introduction of natural, this simple reasoning ecological 
function adequately emphasizes the overall principles and people-centered "Heaven." Now, with the improvement of people's living standards, the ecological environment has also put forward new demands that cycle is a prerequisite to implement the "people-oriented" living environment. And to create a combination of natural and ecological cycle with good living environment, we are required to pay special attention to the natural environment and combined with good local conditions, make the best use of all the factors that can use efficient use of natural resources, reduce labor factors, focus on the design of the natural environment. In addition, the sustainable development of ecological landscapeis intended to seek the harmony of nature, architecture and people between the two. In the "people-oriented", based on the use of natural and artificial, it means to create an environment conducive to people comfortable, healthy life environment, but also to control the use of natural resources, to achieve a balance between the returns obtained from the natural give and return.

\section{THE Role OF Local CUlture IN THE MODERN LANDSCAPE DESIGN}

We talk about local culture, local landscape. The ultimate goal is to create a modern landscape that has local characteristics. Modern professional landscape is over a hundred years of history, but so far, most of all are involved in city related to the current domestic and international landscape design compared to a gap existence. We have a long history and fine tradition of five thousand years, which is rich in natural resources and wisdom of a multi-ethnic, so we have no reason to do bad landscape construction. The landscape is creating on earth; it must respect the traditions, history and culture. Otherwise, it will be considered discordant, which will not be accepted by people, and we will lose value and soil of its existence. Increase over the previous Yunnan Hani Terrace, just respect for tradition, respect for history and culture model. Local is the nation, the nation is the world, we only give full play to landscape design and fine traditions of the ancestors, in order to form their own special landscape.

\section{CONCLUSIONS}

I hope to return to reproduce the natural beauty of nature in the city. The city does not allow more space for the natural beauty to create a "small in the big" "pot of the world," the natural scenery, physical access and natural coordination, mental balance. Return to historical, social and cultural history of accumulation, is the material culture and spiritual culture of crystallization of human nature can intuitively come from their history and culture. History and Culture have been inherited; humans are more like history, culture, and heritage.This is one of the characteristics of the decision itself. (1) People are instinctivelyand psychologically acceptable for their own nation's history and cultural harbor feelings; people have nostalgia, I feel worthy to remember the past, which is a rebellious, topology mentality; this is a continuation of the national culture to accept the historical future, people rely on comparative history to see hope for the future. Therefore, people are more nostalgic history and culture, they like to have historical and cultural significance of the built environment, historical and cultural relic's protection has become part of people's lives. In the modern environmental design, one should keep this cultural continuity, so that the history of landscape architecture reflects certain cultural patterns; on the other hand, the historical events, historical symbol of the association and historical and cultural sites of condensation in buildings historical and cultural landscape can be reproduced. To hightech, high emotional development, the built environment is the technology demonstration stage, a variety of cutting-edge technology, high-tech products on display in the city, a variety of techniques are to convey information to people, marking the advent of the information age, so that the built environment technical content increased. This reflects not only on the composition of space in the architectural landscape of the materialproduction and process of high-tech, high-tech design also includes a method of using computeraided design, which can be simulated in the computer environment. The built environment is in need of high-tech high emotion building space, while people are with technical dealings and the need for communication between people, such as office space and in a small bar, a small seating area is to meet the emotional exchange. The same should set some architectural landscape outdoors to relax tensions.

\section{References}

[1] Wang Siyuan, NiuMeng.Revelation [a] local cultures to Chinese Modern Landscape Design [J] Guangdong Landscape Architecture, 2009,03: 19-22.

[2] Wang Siyuan. Application and revelation of local culture in the modern landscape of China's modern landscape design [J] Beijing Garden, 2009,02: 4-8.

[3] Yang Cheng. Folk culture and modern landscape design [J] Anhui Literature (second half), 2009,10: 170.

[4] Shen Zhiming. Modern Landscape Design - making Inheritance and development trend of innovation [J] Nanping Teachers College, 2004,01: 116-119.

[5] Zhao Dan. China Modern Landscape Design - people, nature, thorough integration of technology [J] Chongqing University of Posts and Telecommunications (Social Sciences), 2005,02: 295-296.

[6] Liu Yujie. Modern landscape planning and design interpretation by Symonds's "Landscape Architecture" about [J] Chinese garden, 2002,01: 19-22.

[7] Jiao Kehua.Modern landscape design embodies the spiritual and cultural China $[\mathrm{J}]$ China Population, Resources and Environment, 2010, S2:..190-193.

[8] TangXianqian. Public toilets and the local culture of urban landscape design [J] Art hundreds, 2007, S1. 102-105. 